\title{
Colonic irrigation for defecation disorders after dynamic graciloplasty
}

\author{
Sacha M. Koch • Özenç Uludağ • Kadri El Naggar • \\ Wim G. van Gemert • Cor G. Baeten
}

Accepted: 26 July 2007 / Published online: 21 September 2007

(C) Springer-Verlag 2007

\begin{abstract}
Background and aims Dynamic graciloplasty (DGP) improves anal continence and quality of life for most patients. However, in some patients, DGP fails and fecal incontinence is unsolved or only partially improved. Constipation is also a significant problem after DGP, occurring in $13-90 \%$. Colonic irrigation can be considered as an additional or salvage treatment for defecation disorders after unsuccessful or partially successful DGP. In this study, the effectiveness of colonic irrigation for the treatment of persistent fecal incontinence and/or constipation after DGP is investigated.

Materials and methods Patients with defecation disorders after DGP visiting the outpatient clinic of the University Hospital Maastricht were selected for colonic irrigation as additional therapy or salvage therapy in the period between January 1999 and June 2003. The Biotrol ${ }^{\circledR}$ Irrimatic pump or the irrigation bag was used for colonic irrigation. Relevant physical and medical history was collected. The patients were asked to fill out a detailed questionnaire about colonic irrigation.

Results Forty-six patients were included in the study with a mean age of $59.3 \pm 12.4$ years $(80 \%$ female). On average, the patients started the irrigation $21.39 \pm 38.77$ months after the DGP. Eight patients started irrigation before the DGP. Fifty-two percent of the patients used the irrigation as additional therapy for fecal incontinence, $24 \%$ for constipation, and $24 \%$ for both. Irrigation was usually performed
\end{abstract}

S. M. Koch • Ö. Uludağ $\cdot$ K. El Naggar $\cdot$ W. G. van Gemert •

C. G. Baeten $(\triangle)$

Department of Surgery, University Hospital Maastricht, P.O. Box 5800, 6202 AZ Maastricht, The Netherlands

e-mail: c.baeten@surgery.azm.nl in the morning. The mean frequency of irrigation was $0.90 \pm$ 0.40 times per day. The mean amount of water used for the irrigation was $2.27 \pm 1.751$ with a mean duration of $39 \pm$ $23 \mathrm{~min}$. Four patients performed antegrade irrigation through a colostomy or appendicostomy, with good results. Overall, $81 \%$ of the patients were satisfied with the irrigation. Thirtyseven percent of the patients with fecal incontinence reached (pseudo-)continence, and in $30 \%$ of the patients, the constipation completely resolved. Side effects of the irrigation were reported in $61 \%$ of the patients: leakage of water after irrigation, abdominal cramps, and distended abdomen. Seven (16\%) patients stopped the rectal irrigation.

Conclusion Colonic irrigation is an effective alternative for the treatment of persistent fecal incontinence after DGP and/or recurrent or onset constipation additional to unsuccessful or (partially) successful DGP.

Keywords Colonic irrigation · Fecal incontinence ·

Constipation $\cdot$ Dynamic graciloplasty

\section{Introduction}

Dynamic graciloplasty (DGP) is a proven effective treatment for fecal incontinence. Success rates vary from 42 $92 \%$ [1-5]. Comparison of results is difficult because the outcome of this method seems to be influenced by the etiology of fecal incontinence, pre-existing stoma, length of follow-up, method of stimulation, and the surgeon's experience $[1,6]$. DGP significantly improves quality of life and anal continence for most patients [2]. Quality of life and patient satisfaction scores correlate significantly with continence scores [7, 8]. However, in some patients, fecal incontinence is unsolved or only partially improved after DGP. 
Morbidity rates are high after DGP: complications associated with the technique can often be prevented or treated, but other complications like reduced sensitivity of the rectum by destruction of sensory nerves can be very hard to treat and often result in DGP failure $[4,8,9]$. Morbidity rates are lower and success rates higher in the hands of surgeons experienced in the technique $[3,10]$.

Constipation is a significant problem after graciloplasty, occurring in $13-90 \%$ of the patients after DGP $[6-8,11$, 12]. Constipation due to technical failure, like a gracilis wrap that is too tight, can be treated by revisional surgery. Other causes of constipation can first be treated with dietary measures and medication. In case of pelvic floor dysfunction, biofeedback training can be started [9]. When this first line treatment is unsuccessful, retrograde colonic irrigation can be considered. Colonic irrigation can also be used as an additional therapy or salvage therapy for persistent fecal incontinence after failed or partially failed surgery [13]. Not much is known about the success rate of retrograde colonic irrigation, as there is only a limited number of published studies [13, 14].

Antegrade irrigation through a colostomy or appendicocecostomy is another technique for colonic irrigation, with a reasonable success rate of $64-85 \%$ [15-17].

In this study, the effectiveness of colonic irrigation for the treatment of persistent fecal incontinence and/or constipation after DGP was investigated.

\section{Materials and methods}

Patients with DGP and postoperative defecation disorders were selected for colonic irrigation between January 1999 and June 2003. The patients were offered colonic irrigation as additional or salvage therapy, as a colostomy was the final option for these patients. The inclusion criteria were invalidating fecal incontinence and/or constipation after DGP and a signed informed consent; exclusion criteria were patients not willing to perform the irrigation because of either embarrassment or wish for colostomy or patients physically and/or mentally not capable of performing irrigation.

All patients visited the outpatient clinic of the University Hospital Maastricht. Relevant physical and medical history were collected. The patients could be divided in six groups according to the etiology of fecal incontinence before DGP: congenital, trauma (rupture/anal surgery), pudendopathy (PNTML $>2.6 \mathrm{~ms}$ ), spinal cord lesion, cancer (abdominal perineal resection in rectumcarcinoma), and prolapse. The patients were asked to fill out a questionnaire. This questionnaire contained questions concerning the method of irrigation, the time needed for irrigation, the amount of water used, the frequency of irrigation, added substances to the irrigation water, and side effects of colonic irrigation. The endpoint was defined that irrigation had to be successful and satisfying for the patients. Successful irrigation was defined as reaching continence for feces (pseudo-continence) and/or complete resolution of straining, feeling of incomplete evacuation, bloating abdomen, and abdominal pain during irrigation.

The patient was considered satisfied when he or she indicated that the colonic irrigation rendered a major improvement of the quality of life. The improvement of quality of life was measured by a visual analog scale/ specific questions within the questionnaire. The irrigation was performed in most patients as retrograde irrigation; only four patients performed antegrade irrigation through an appendico-cecostomy or a colostomy. Patients with fecal incontinence can gain continence as a result of colonic irrigation. This is called pseudo-continence because these patients are only continent, as there is no fecal filling of the rectum and distal colon. The definition of resolved constipation was no straining and no feeling of incomplete evacuation after defecation. Defecation occurred during irrigation in most of these patients.

The Biotrol ${ }^{\circledR}$ Irrimatic pump (Braun ${ }^{\circledR}$; Fig. 1) or the irrigation bag (Braun ${ }^{\circledR}$; Fig. 2) were used for colonic irrigation. The Irrimatic pump is an irrigation pump using a flexible tube with a cone-shaped end. The tube is introduced either in the anal canal in case of retrograde irrigation or placed in an appendico-cecostomy or colostomy in case of antegrade irrigation. The pump can hold a maximum of 21 . The patients were instructed to start the irrigation daily with $500 \mathrm{ml}$ of water. Thereafter, the frequency and the amount of water were adjusted until a satisfactory result was achieved. Water used for irrigation was at body temperature; too cold water can cause abdominal cramps or collapse and too hot water can cause burns. Soap or laxatives could be added if necessary. The

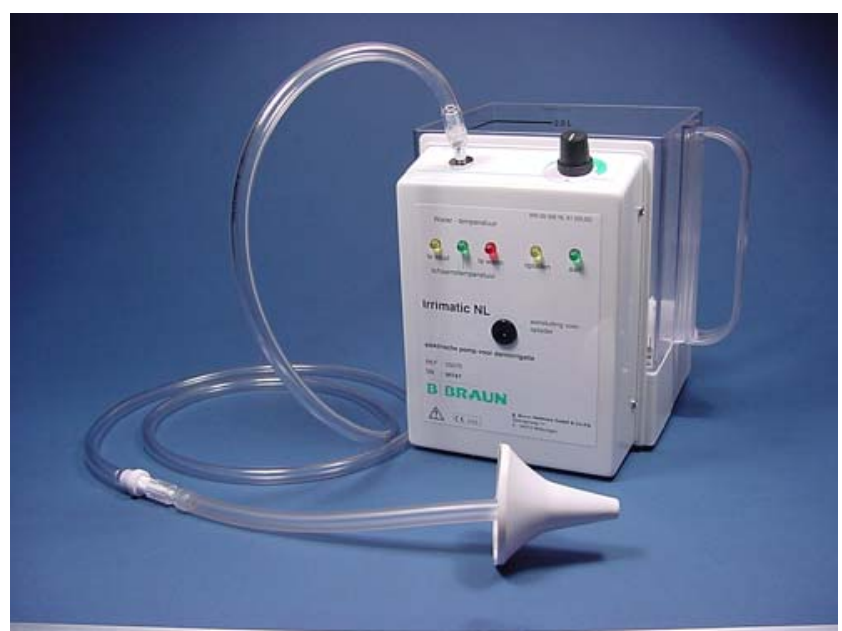

Fig. 1 Biotrol ${ }^{\mathbb{R}}$ Irrimatic pump (Braun ${ }^{\mathbb{R}}$ ) 


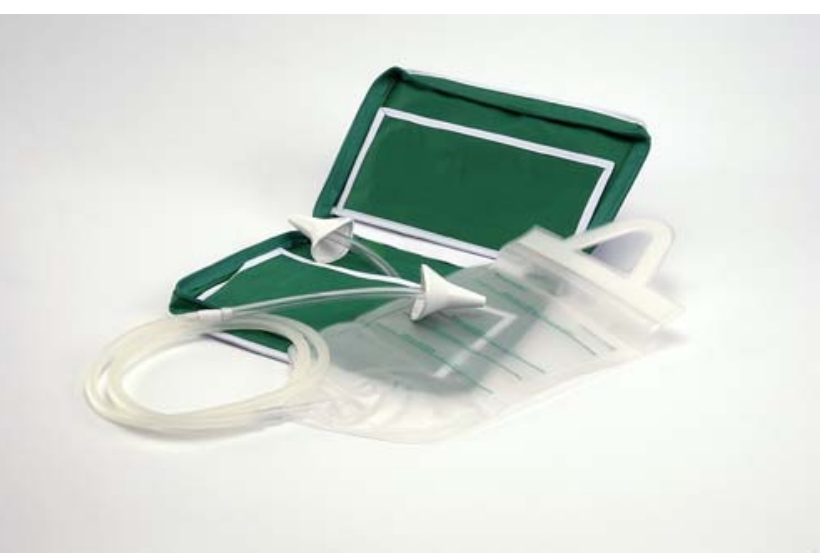

Fig. 2 Irrigation bag $\left(\operatorname{Braun}^{\circledR}\right)$

pump works on a storage battery, and the speed of water ejection can be regulated. The working mechanism of the irrigation bag is similar, except for the water ejection, which is induced by gravity.

Data analysis was performed by using SPSS 14.0 (SPSS release 14.0, SPSS, Chicago, USA), with the MannWhitney $U$ test. $P \leq 0.05$ was considered statistically significant. Data are given as the mean values with the standard deviation.

\section{Results}

The questionnaire was sent to 74 patients. Fourteen patients did not wish to participate in the study for various reasons, and 14 patients did not return the questionnaire. Forty-six patients $(62 \%)$ could be included for analysis of which 37 were female $(80 \%)$, and these patients had an overall mean age of $59.3 \pm 12.4$ years. Complications of the DGP occurred in $23(50 \%)$ patients of which 10 patients had two or more complications. Twenty-two patients suffered from constipation, 35 patients were still incontinent for feces, and seven patients had pain in the IPG pocket, leg, or anus.

The medical history besides the DGP is mentioned in Table 1. On average, the patients started the irrigation $21.39 \pm$ 38.77 months after the DGP. Eight patients already used irrigation before DGP.

Twenty-four (52\%) patients used irrigation as an additional therapy for fecal incontinence in partially failing DGP. Eleven (24\%) patients used irrigation for constipation and $11(24 \%)$ patients for both. Most patients (91\%) used the irrigation pump. Three patients added soap and one patient an enema to the water to achieve a better result. These were patients with constipation or a combination of fecal incontinence and constipation.

Irrigation was usually performed in the morning (70\%) and sometimes in the evening (16\%). The frequency of irrigation was $0.90 \pm 0.40$ times per day. The amount of water used for irrigation was $2.27 \pm 1.751$ with duration of $39 \pm 23 \mathrm{~min}$. Seventy-four percent of the patients with fecal incontinence irrigated in the morning, $17 \%$ in the evening, and $9 \%$ twice a day. For the patients with constipation, these numbers are, respectively, 45,18 , and $36 \%$. Ninety percent of the patients with a combination of defecation disorders used the colonic irrigation in the morning.

There was no significant difference in the frequency of irrigation between patients with fecal incontinence and patients with constipation ( 0.92 vs $0.98 /$ day; $P=0.108)$. The amount of water used for irrigation was higher in patients with fecal incontinence compared to patients with constipation, but this difference was not significant (2.31 vs $1.911 ; P=0.484)$. There was no significant difference in the time needed for irrigation between patients with fecal incontinence and those with constipation (40.8 vs 32.9 min; $P=0.154$ ).

Overall, $81 \%$ of the patients were satisfied with the irrigation, $80 \%$ of the patients with fecal incontinence, $90 \%$ of the patients with constipation, and $72 \%$ of the patients with a combined defecation disorder. Thirty-seven percent of the patients with fecal incontinence reached (pseudo-) continence, and in $30 \%$ of the patients, the constipation completely resolved (Fig. 3). In $29 \%$ of the patients with a combined defecation disorder, the constipation resolved and they were (pseudo-) continent. Overall, satisfaction was related with symptomatic improvement. Only one patient with good symptomatic improvement was not satisfied because he felt that the irrigation was time-consuming and not practical.

Four patients, two with fecal incontinence, one with constipation, and one with both, performed antegrade irrigation through a (3) colostomy or an (1) appendicocecostomy with good results, and all indicated that the irrigation improved their quality of life.

The patients could be divided in six groups according to the underlying cause of fecal incontinence before DGP (Table 2). When the different etiologies before DGP were compared with the result during irrigation, the patients with

Table 1 Medical history

\begin{tabular}{ll}
\hline Medical history & $\begin{array}{l}\text { Number of patients } \\
\text { (percentage of total) }\end{array}$ \\
\hline Anal rupture during delivery & $13(28 \%)$ \\
Anal repair & $14(30 \%)$ \\
Prolapse operation & $19(41 \%)$ \\
Hysterectomy & $17(37 \%)$ \\
Abdomino-perineal resection for & $8(17 \%)$ \\
$\quad$ rectum carcinoma & $2(9 \%)$ \\
Sigmoid resection for sigmoiditis & $8(17 \%)$ \\
Cholecystectomy & $1(2 \%)$ \\
Anus atresia &
\end{tabular}


Fig. 3 Success of rectal irrigation for defecation disorders

\section{incontinence}

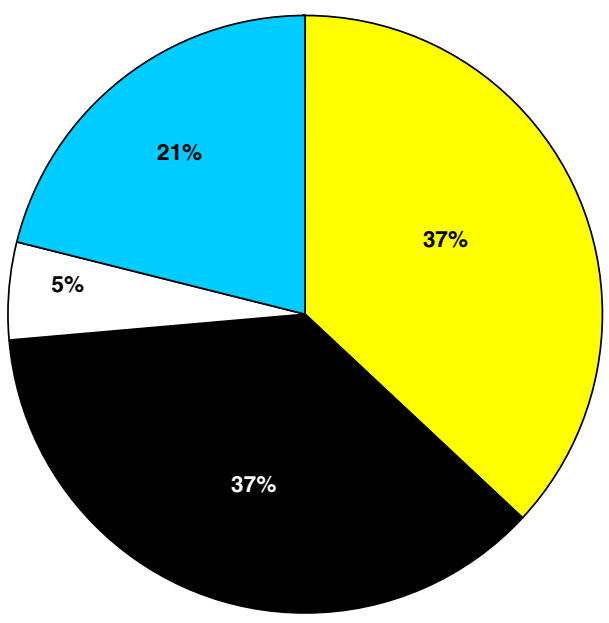

$\square$ continent
$\square$ sometimes incontinent
$\square$ often incontinent
$\square$ no change

\section{constipation}

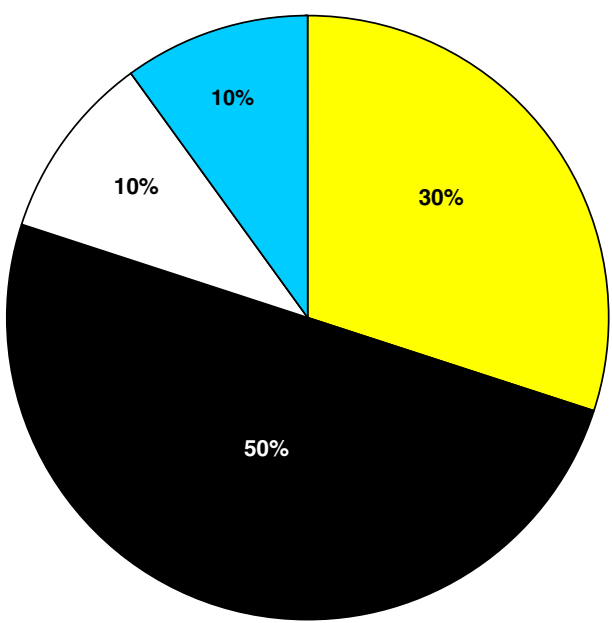

a rupture or anal surgery had the worst results of irrigation. The patients with a spinal cord lesion seemed to have the best results.

Side effects of the irrigation were reported in $61 \%$ of the patients: leakage of water after irrigation (43\%), abdominal cramps (17\%), and distended abdomen (17\%). Twenty-four (53\%) patients changed the irrigation method during their course to improve the results. Seven (16\%) patients stopped the rectal irrigation: in five patients, the result was unsatisfactory; two other patients did not need the irrigation anymore because the complaints resolved completely. Finally, two patients received a permanent stoma.

\section{Discussion}

Colonic irrigation can be used effectively to treat defecation disorders when other conservative treatments fail or in addition to unsuccessful or partially successful surgical treatment [18].

Colonic irrigation is usually forgotten as an alternative conservative treatment for defecation disorders, although many health care takers are familiar with colonic irrigation, particularly, for its use as perioperative colonic cleansing $[19,20]$.

Retrograde colonic irrigation is performed through the anorectum or via a colostomy. Only a few publications addressed to retrograde colonic irrigation are found in literature. Briel et al. [13] found a success rate of $38 \%$ of retrograde colonic irrigation for fecal incontinence and a significant improvement in quality of life. Recently, another study reported a success rate of $41 \%$ in patients with fecal incontinence and $65 \%$ in patients with constipation [18]. The success rate is based on patient satisfaction. Although patient satisfaction is the primary goal of treatment, it is a subjective measure. In future research, this should be combined with objective measures such as validated quality of life questionnaires in a prospective study design.

Antegrade colonic irrigation is especially known for the treatment of evacuation disorders in small children and can be performed through an appendico-cecostomy (MACE) or a cecostomy button [16, 21-23]. Alternative enteral access is a sigmoid tube or transverse colonic conduit for patients with a left colonic evacuation disorder [24-26]. The most

Table 2 Success of rectal irrigation in different etiologies for fecal incontinence before DGP

\begin{tabular}{lll}
\hline Etiology & $\begin{array}{l}\text { Number of } \\
\text { cases }\end{array}$ & $\begin{array}{l}\text { Success (\%) } \\
\text { during irrigation }\end{array}$ \\
\hline Congenital & 1 & $1(100 \%)$ \\
Trauma & 14 & $3(21 \%)$ \\
Pudendopathy & 15 & $5(33 \%)$ \\
Spinal cord lesion & 5 & $3(60 \%)$ \\
$\begin{array}{l}\text { Abdomino-perineal resection for } \\
\text { rectum carcinoma }\end{array}$ & 8 & $3(37 \%)$ \\
$\begin{array}{l}\text { Prolapse } \\
\text { Total }\end{array}$ & 2 & $0(0 \%)$ \\
\hline
\end{tabular}


common problems of MACE are stoma stenosis and leakage $[16,17]$. The results in our hospital of antegrade irrigation by an appendico-cecostomy were described earlier [23]. In this study, four patients performed antegrade irrigation via a colostomy or a MACE with good results. O'Bichere et al. performed an experimental study investigating the effect of retrograde vs antegrade colonic irrigation in pigs. That study demonstrates that colonic emptying is more efficient with antegrade irrigation compared to retrograde irrigation [27]. Although a reasonable success rate can be achieved with antegrade irrigation (64-85\%) [15-17], retrograde colonic irrigation is preferred above antegrade irrigation as initial treatment because of its non-invasive nature and benign complications.

The amount of water used for irrigation was higher in patients with fecal incontinence compared to patients with constipation. This can be explained by the difficulty of retaining water in the rectum in case of fecal incontinence. Theoretically, the amount of water retained in the rectum is higher in patients with constipation. The grade of colonic emptying by irrigation in constipated patients by means of scintigraphy was investigated by Christensen et al. [14]. The effect of retrograde colonic washout was significantly better in idiopathic fecal incontinence compared to idiopathic constipation, and its effect correlated with the extent to which the irrigation fluid had entered the colorectum.

Surgical treatment of fecal incontinence gives an overall success of $50-84 \%$, depending on the etiology of fecal incontinence and type of surgical procedure [28-32]. Success percentages in DGP vary from 42-92\% [1-5]. The success rate of $80 \%$ of colonic irrigation is comparable to the success rate of surgical treatment for fecal incontinence. Sixty-one percent of the patients that received the questionnaire completed it. Even when we assume that the patients who did not complete the questionnaire were dissatisfied with the treatment (bad case scenario), the success rate in the present study would still be $50 \%$. It is important to realize that this is a selected group of patients with persistent incontinence and/or constipation after DGP. Regarding the fecal incontinence, this group of patients represents the 8-58\% (assuming 42-92\% success after DGP) with insufficient results of DGP [1-5].

Regarding the different underlying causes for fecal incontinence before DGP, the patients with a trauma to the anal sphincter have the lowest success rate and the patients with a spinal cord lesion have the highest success rate. It is not possible to draw conclusions about the statistical significance of these results because of the limited group size.

Previous studies already reported an increased incidence of constipation after DGP [3, 6, 8, 11, 12].

In this study, we included 22 patients that were constipated after DGP, of which 11 patients had constipa- tion in combination with persistent fecal incontinence. It is important to realize that many patients are incontinent for feces after periods of severe evacuation problems. These evacuation problems are present again after treatment of the fecal incontinence. Its etiology is not well understood, but is likely to be multifactorial [33, 34]. This is known after all surgical procedures for fecal incontinence [35]. Constipation can be due to technical problems such as a tight graciloplasty, which can be solved by revision of the DGP. It is also possible that nerve tissue around the anus sustains damage during the operation, causing pudendopathy which cannot be treated by revisional surgery. Previous surgery in the pelvis, like an abdomino-perineal resection (eight patients in this study), is known to have a very high rate of obstructed defecation, probably due to reduced rectal sensitivity and pelvic floor dysfunction [36]. Constipation related to physical impairment, like a disturbed sensation and/or motility because of a congenital cause or degeneration, is difficult to treat [9]. These patients are usually served well with colonic irrigation.

Surgical treatment of constipation is troublesome and only indicated in a selected group of patients with intractable constipation. The bowel frequency usually increases, but abdominal pain and bloating persists in most patients [37]. In this study, $90 \%$ of the patients were satisfied with the irrigation, and in $30 \%$, the constipation resolved with colonic irrigation.

The final step of treatment after the colonic irrigation in the patients of this study would be a colostomy or ileostomy. In the study of Norton et al., the majority of the patients with fecal incontinence managed by a colostomy reported to be positive about the stoma. However, a few could not adapt to the stoma and disliked it intensely [38]. Harris et al. investigated patients with fecal incontinence or constipation managed with a stoma. Many of these patients reported that lifestyle restrictions were imposed by the stoma, and almost half of the patients felt stigmatized. Up to a third of these patients had significant depression, especially the younger women [39]. Cultural issues also have an important impact on the acceptance of a stoma [40]. Keeping these disadvantages of a definitive stoma in mind, colonic irrigation offers an attractive alternative, which is worthwhile trying before proceeding to a definitive stoma.

\section{Conclusion}

Colonic irrigation is an effective alternative for the treatment of persistent fecal incontinence after DGP and/or recurrent or onset constipation additional to unsuccessful or (partially) successful DGP. Colonic irrigation is an undervalued and often forgotten treatment option, which deserves its rightful place among the other treatment modalities. 


\section{References}

1. Mavrantonis C, Billotti VL, Wexner SD (1999) Stimulated graciloplasty for treatment of intractable fecal incontinence: critical influence of the method of stimulation. Dis Colon Rectum 42:497-504

2. Wexner SD, Baeten C, Bailey R et al (2002) Long-term efficacy of dynamic graciloplasty for fecal incontinence. Dis Colon Rectum 45:809-818

3. Baeten CG, Bailey HR, Bakka A et al (2000) Safety and efficacy of dynamic graciloplasty for fecal incontinence: report of a prospective, multicenter trial. Dynamic Graciloplasty Therapy Study Group. Dis Colon Rectum 43:743-751

4. Chapman AE, Geerdes B, Hewett P et al (2002) Systematic review of dynamic graciloplasty in the treatment of faecal incontinence. Br J Surg 89:138-153

5. Penninckx F (2004) Belgian experience with dynamic graciloplasty for faecal incontinence. Br J Surg 91:872-878

6. Ortiz H, Armendariz P, DeMiguel M et al (2003) Prospective study of artificial anal sphincter and dynamic graciloplasty for severe anal incontinence. Int J Colorectal Dis 18:349-354

7. Baeten CG, Geerdes BP, Adang EM et al (1995) Anal dynamic graciloplasty in the treatment of intractable fecal incontinence. $\mathrm{N}$ Engl J Med 332:1600-1605

8. Thornton MJ, Kennedy ML, Lubowski DZ et al (2004) Long-term follow-up of dynamic graciloplasty for faecal incontinence. Colorectal Dis 6:470-476

9. Geerdes BP, Heineman E, Konsten J et al (1996) Dynamic graciloplasty. Complications and management. Dis Colon Rectum 39:912-917

10. Madoff RD, Rosen HR, Baeten CG et al (1999) Safety and efficacy of dynamic muscle plasty for anal incontinence: lessons from a prospective, multicenter trial. Gastroenterology 116:549-556

11. Matzel KE, Madoff RD, LaFontaine LJ et al (2001) Complications of dynamic graciloplasty: incidence, management, and impact on outcome. Dis Colon Rectum 44:1427-1435

12. Rosen HR, Urbarz C, Novi G et al (2002) Long-term results of modified graciloplasty for sphincter replacement after rectal excision. Colorectal Dis 4:266-269

13. Briel JW, Schouten WR, Vlot EA et al (1997) Clinical value of colonic irrigation in patients with continence disturbances. Dis Colon Rectum 40:802-805

14. Christensen P, Olsen N, Krogh K et al (2003) Scintigraphic assessment of retrograde colonic washout in fecal incontinence and constipation. Dis Colon Rectum 46:68-76

15. Kokoska ER, Keller MS, Weber TR (2001) Outcome of the antegrade colonic enema procedure in children with chronic constipation. Am J Surg 182:625-629

16. Cascio S, Flett ME, De la Hunt M et al (2004) MACE or caecostomy button for idiopathic constipation in children: a comparison of complications and outcomes. Pediatr Surg Int 20:484-487

17. Schell SR, Toogood GJ, Dudley NE (1997) Control of fecal incontinence: continued success with the Malone procedure. Surgery 122:626-631

18. Gosselink MP, Darby M, Zimmerman DD et al (2005) Long-term follow-up of retrograde colonic irrigation for defaecation disturbances. Colorectal Dis 7:65-69
19. Wolters U, Keller HW, Sorgatz S et al (1994) Prospective randomized study of preoperative bowel cleansing for patients undergoing colorectal surgery. Br J Surg 81:598-600

20. Vincent MV, Marven SS (2004) Intraoperative colonic lavage in infants using a Replogle tube. Pediatr Surg Int 20:562-563

21. Malone PS, Ransley PG, Kiely EM (1990) Preliminary report: the antegrade continence enema. Lancet 336:1217-1218

22. Malone PS, Curry JI, Osborne A (1998) The antegrade continence enema procedure why, when and how. World J Urol 16:274-278

23. Rongen MJ, van der Hoop AG, Baeten CG (2001) Cecal access for antegrade colon enemas in medically refractory slow-transit constipation: a prospective study. Dis Colon Rectum 44:16441649

24. Gauderer MW, Decou JM, Boyle JT (2002) Sigmoid irrigation tube for the management of chronic evacuation disorders. J Pediatr Surg 37:348-351

25. Heriot AG, Tilney HS, Simson JN (2002) The application of percutaneous endoscopic colostomy to the management of obstructed defecation. Dis Colon Rectum 45:700-702

26. Hughes SF, Williams NS (1995) Continent colonic conduit for the treatment of faecal incontinence associated with disordered evacuation. Br J Surg 82:1318-1320

27. O'Bichere A, Sibbons P, Dore C et al (2002) Experimental study of faecal continence and colostomy irrigation. Br J Surg 87:902908

28. Vaizey CJ, Kamm MA, Roy AJ et al (2000) Double-blind crossover study of sacral nerve stimulation for fecal incontinence. Dis Colon Rectum 43:298-302

29. Matzel KE, Stadelmaier U, Hohenfellner M et al (1995) Electrical stimulation of sacral spinal nerves for treatment of faecal incontinence. Lancet 346:1124-1127

30. Uludag O, Darby M, Dejong CH et al (2002) Sacral neuromodulation is effective in the treatment of fecal incontinence with intact sphincter muscles; a prospective study. Ned Tijdschr Geneeskd 146:989-993

31. Rotholtz NA, Wexner SD (2001) Surgical treatment of constipation and fecal incontinence. Gastroenterol Clin North Am 30:131166

32. Uludag O, Koch SM, van Gemert WG et al (2004) Sacral Neuromodulation in patients with fecal incontinence, a single centre study. Dis Col Rectum 47:1350-1357

33. Koch SM, Uludag O, Rongen MJ et al (2004) Dynamic graciloplasty in patients born with anal atresia. Dis Colon Rectum 47:1711-1719

34. Mander BJ, Wexner SD, Williams NS et al (1999) Preliminary results of a multicentre trial of the electrically stimulated gracilis neoanal sphincter. Br J Surg 86:1543-1548

35. Geerdes BP, Konsten J, Baeten CG (1996) Constipation after dynamic graciloplasty. Dis Colon Rectum 39:943

36. Christiansen J, Rasmussen O, Lindorff-Larsen K (1998) Dynamic graciloplasty for severe anal incontinence. Br J Surg 85:88-91

37. Pfeifer J, Agachan F, Wexner SD (1996) Surgery for constipation. Dis Colon Rectum 39:444-460

38. Norton C, Burch J, Kamm MA (2005) Patients' views of a colostomy for fecal incontinence. Dis Col Rectum 48:1062-1069

39. Harris R, Daly K, Jones L, Kiff E (2004) Stoma formation for functional bowel disease. Colorectal Dis 6:280-284

40. Black P (2004) Psychological, sexual and cultural issues for patients with a stoma. Br J Nurs 13:692-697 